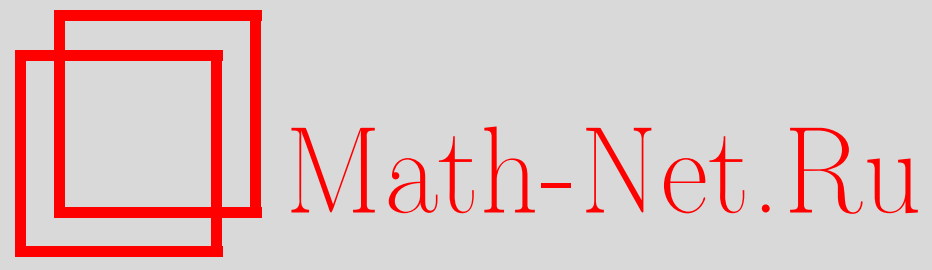

И. В. Волович, Памяти Василия Сергеевича Владимирова, Вестн. Сам. гос. техн. ун-та. Сер. Физ.-мат. науки, 2012, выпуск 4(), 8-16

DOI: https://doi.org/10.14498/vsgtu1208

Использование Общероссийского математического портала Math-Net.Ru подразумевает, что вы прочитали и согласны с пользовательским соглашением

http://www.mathnet.ru/rus/agreement

Параметры загрузки:

IP : 35.173 .219 .149

26 апреля 2023 г., 14:12:22

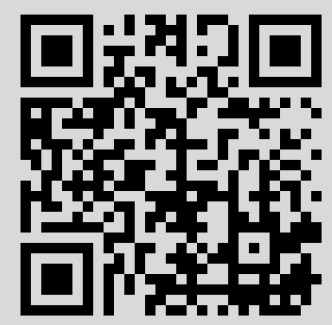




\section{Памяти \\ Василия Сергеевича Владимирова}

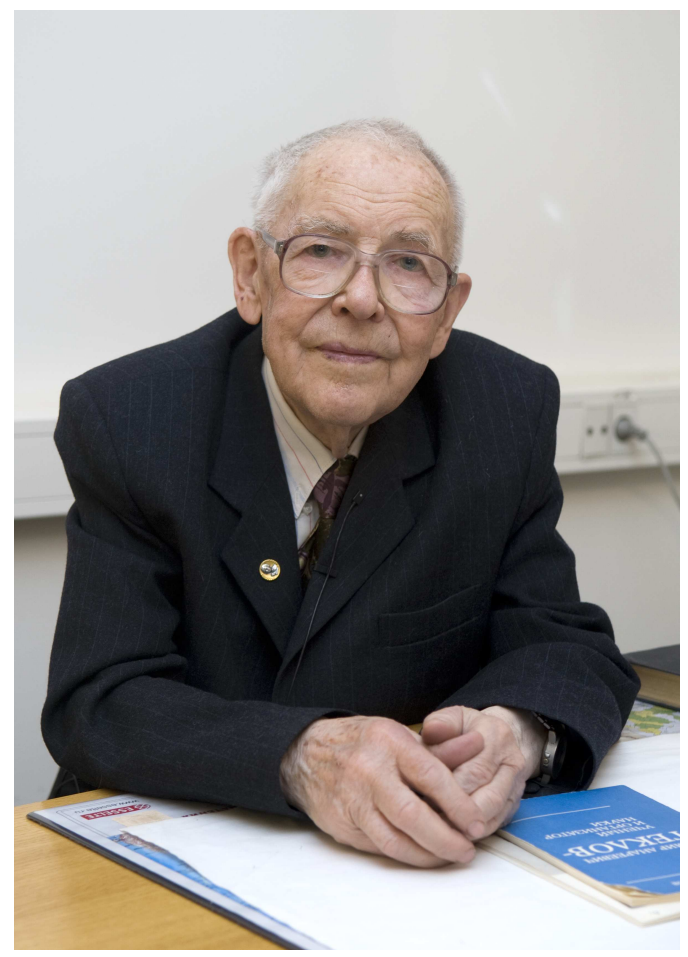

$(09.01 .1923-03.11 .2012)$

3 ноября 2012 г. на девяностом году жизни скончался выдающийся учёный, действительный член Российской Академии наук, Герой Социалистического труда, Лауреат Государственных премий, иностранный член нескольких академий и обществ, бывший директор Математического института им. В. А. Стеклова РАН, профессор Московского физико-технического института, участник Великой Отечественной войны Василий Сергеевич Владимиров, учёный с мировым именем, активный пропагандист математической науки, основоположник одной из ведущих школ в области математической физики.

Василий Сергеевич Владимиров родился 9 января 1923 г. в деревне Дяглево Петроградской губернии в крестьянской семье. Жизненный путь Василия Сергеевича начинался так же, как и у многих его сверстников. Начало его учебы совпало с началом коллективизации и последующим голодом. В школу пошёл в 7 лет в 1930 г., в 16 лет поступает в Ленинградский университет на физический факультет.

С началом Великой Отечественной войны в июле-августе 1941 г. Василий Сергеевич участвовал в оборонных работах под Ленинградом. В конце августа 1941 г. он был призван в ряды Красной Армии и направлен курсантом в Военно-автомобильное училище ВВС ЛФ. Рядовым солдатом Василий 
Сергеевич прошёл всю войну до победы. С ноября 1941 г. по декабрь 1944 г. воевал на Ленинградском фронте на различных военных авиабазах, с декабря 1944 г. по октябрь 1945 г. служил в системе ПВО Ленинграда. Василий Сергеевич - участник героической обороны и прорыва блокады Ленинграда, пережил ужасы блокадного голода и холода.

В октябре 1945 г. Василий Сергеевич, демобилизовавшись из армии в звании старшины запаса, продолжает учебу в Ленинградском университете, но уже на механико-математическом факультете. В 1948 г. он с отличием окончил университет по кафедре теории чисел и был рекомендован в аспирантуру.

Первые работы Василия Сергеевича относятся к геометрической теории чисел, которой он занимался под руководством Бориса Алексеевича Венкова.

В 1948 г. Василий Сергеевич поступает на работу младшим научным сотрудником в Ленинградское отделение Математического института им. В. А. Стеклова. В то время наша страна нуждалась в создании атомного оружия, и Родина опять призвала Василия Сергеевича, но на этот раз как математика. Сначала он занимается расчётами критических параметров простейших ядерных систем под руководством Л. В. Канторовича. Типичной была чисто математическая задача определения радиуса шара, окружённого одной или двумя оболочками, при котором уравнение Пайерлса имеет положительное решение. После успешного испытания 29 августа 1949 г. первой советской атомной бомбы РДС-1 младший научный сотрудник В. С. Владимиров был премирован Советом Министров крупной денежной суммой.

В ноябре 1950 г. Владимиров был направлен на работу в КБ-11 - теперешний Российский федеральный ядерный центр - ВНИИЭФ (Арзамас 16). ${ }^{1}$

Там он начал работать под руководством Н. Н. Боголюбова, что положило начало их дальнейшему многолетнему плодотворному сотрудничеству. Василий Сергеевич руководит большой группой математиков и вычислителей, работает над заданиями Е. И. Тамма, А. Д. Сахарова, Я. Б. Зельдовича, Ю. Б. Харитона и других. Был выполнен ряд важных численных расчётов, при этом возникали новые математические задачи, для решения которых требовалась разработка принципиально новых подходов, привлечение «высокой» математики и изобретательности.

В 1951-52 гг. Василием Сергеевичем был разработан и успешно реализован на практике новый метод численного решения краевых задач для уравнения переноса нейтронов по характеристикам, который теперь называется методом Владимирова. В 1951-53 гг. с использованием этого метода были успешно рассчитаны десятки вариантов многослойных зарядов для водородной бомбы, в частности РДС-6с. Впоследствии метод Владимирова нашёл различные применения и в многомерных задачах нейтронной физики, например, при расчётах ядерных реакторов. 23 июня 1953 г. Василий Сергеевич защитил кандидатскую диссертацию по результатам теоретических исследований и по численному решению методом характеристик односкоростного уравнения переноса для многослойного шара. В ней же была доказана сходимость предложенного метода. Научным руководителем был Н. Н. Боголюбов, официальными оппонентами - С. Л. Соболев и К. А. Семендяев. После успешного испытания первого водородного устройства РДС-6с 12 августа

\footnotetext{
${ }^{1}$ Приволжская контора Главгорстроя СССР - так написано в его трудовой книжке (1954 г.).
} 
1953 г. В. С. Владимирову была присуждена Сталинская премия и присвоено звание Лауреата Сталинской премии, он был признан одним из разработчиков первой атомной бомбы (РДС-1).

В 1954 г. Василий Сергеевич разрабатывает метод факторизации для численного решения краевых задач для многослойного уравнения диффузии (модельный пример опубликован в работе 1955 г.). В течение 1954-55 гг. этим методом были рассчитаны десятки вариантов многослойных сферических задач на замедление нейтронов в диффузном приближении со сложным энергетическим спектром. Эти результаты использовались, в том числе, для расчётов водородной бомбы РДС-37. Метод является альтернативой методу матричной факторизации (прогонки). Сущность метода Владимирова состоит в том, что сначала факторизуется дифференциальный оператор 2-го порядка на устойчивые множители 1-го порядка с помощью неизвестной функции, удовлетворяющей уравнению Риккати, и затем к ним применяются разностные схемы.

С января 1955 г. Василий Сергеевич был зачислен старшим научным сотрудником ЦНИИ-58 и принял участие в разработке малогабаритного атомного заряда (РДС-41) под руководством М. А. Лаврентьева. Задачи переноса нейтронов в цилиндрически симметричных областях, с которыми ему пришлось иметь дело в процессе этой работы, стимулировали его занятия методом Монте-Карло. Василием Сергеевичем опубликована первая в нашей стране работа по методу Монте-Карло.

При работе по ядерному проекту ярко проявилась характерная черта научного творчества Василия Сергеевича - гармоничное сочетание теоретических и прикладных аспектов рассматриваемых задач. Так, были впервые доказаны теоремы единственности, существования и гладкости решения односкоростного уравнения переноса, установлены свойства собственных значений и собственных функций, новый вариационный принцип Владимирова. Применяя новый вариационный принцип к методу сферических гармоник, удалось вывести наилучшие граничные условия для этого метода, которые в одномерном случае в точности совпали с известными условиями Маршака, найденными им эмпирическим путём (условия Маршака-Владимирова).

По результатам теоретических исследований, опубликованных в 1956-58 гг., Василием Сергеевичем была защищена докторская диссертация на открытом Учёном совете Математического института им. В. А. Стеклова АН СССР. Докторская диссертация опубликована в известной монографии «Математические задачи односкоростной теории переноса частиц» и стала настольной книгой сотрудников многих институтов, работающих над атомным проектом. За эту работу Президиум АН СССР присудил В. С. Владимирову Золотую медаль Ляпунова (1971 г.).

Большое научное влияние на Василия Сергеевича оказал Гурий Иванович Марчук, который в то же самое время в Обнинске создавал свои хорошо известные теперь методы расчёта ядерных реакторов. Взаимный обмен информацией по родственным областям науки существенно стимулировал творческую деятельность этих выдающихся учёных - друзей со студенческих лет учёбы в Ленинградском университете.

В 1956 г. В. С. Владимиров возвращается в Москву, в Математический институт им. В. А. Стеклова, и начинается новый этап его научной дея- 
тельности. K этому времени выяснилось, что для решения принципиальных проблем квантовой теории поля, таких как проблема расходимостей и проблема сильных взаимодействий, недостаточно аппарата классической математической физики, а требуется привлечение новых современных разделов математики: многомерного комплексного анализа, теории обобщённых функций, групп Ли. Василий Сергеевич одним из первых вслед за своим учителем Н. Н. Боголюбовым активно включился в разработку этих новых направлений в бурно развивающейся области науки, находящейся на стыке математики и теоретической физики, - в современной математической физике.

В аксиоматической квантовой теории поля, созданной Н. Н. Боголюбовым, возникла задача построения оболочек голоморфности для областей специального вида, определяемых аксиомами. В связи с этим была доказана теорема Владимирова «о $C$-выпуклой оболочке» (1961 г.), существенно дополняющая теорему «об острие клина» Боголюбова. Обе эти теоремы нашли широкое применение как в квантовой теории поля, так и в математике, в частности, при доказательстве теорем о несуществовании элементарной длины, об изоморфизме алгебр, наблюдаемых в области и в её $V$-выпуклой оболочке, о квазианалитических классах обобщённых функций, о единственности решений уравнений в свёртках, об обобщениях теоремы Лиувилля, о представлении Йоста-Лемана-Дайсона и его обобщениях (1963г.).

Первые работы В. С. Владимирова по аксиоматической квантовой теории поля, выполненные частично совместно с Н. Н. Боголюбовым, а также с А. А. Логуновым, относятся к обоснованию дисперсионных соотношений для различных процессов рассеяния элементарных частиц (1958-59 гг.). В двух совместных с Н. Н. Боголюбовым работах установлена частичная зависимость между аксиомами спектральности, Пуанкаре-ковариантности и причинности, которая формулируется в виде теоремы Боголюбова-Владимирова о «конечной ковариантности» $(1958,1971$ гг.). Вместе с Н. Н. Боголюбовым и А. Н. Тавхелидзе им была показана совместимость с общими принципами локальной квантовой теории поля, наблюдаемого на экспериментах масштабно-инвариантного (автомодельного) поведения форм-факторов глубоко неупругого лептон-адронного рассеяния (1972 г.).

В 1960 г. Василий Сергеевич выполнил оригинальную работу «О приближённом вычислении винеровских интегралов», в которой предложена одна из наиболее удобных квадратурных формул для бесконечно-кратных интегралов. Эта работа послужила источником многих дальнейших исследований. Изучая преобразование Лапласа обобщённых функций медленного роста с носителем, ограниченным со стороны острого конуса, Василий Сергеевич дал детальное описание соответствующей алгебры голоморфных функций. В этих алгебрах им была решена задача линейного сопряжения, причём оказалось, что в многомерном случае она имеет нулевой индекс (1965 г.), получено интегральное представление типа Бохнера (1969 г.), а также изучены индикатрисы роста функций в трубчатых областях над выпуклым конусом (1965-66 гг.). Свои исследования по приложениям многомерного комплексного анализа и теории обобщённых функций к квантовой теории поля и к другим проблемам математической физики Василий Сергеевич изложил в известной монографии «Методы теории функций многих комплексных переменных» (1964г.), переведённой в США и во Франции. 
В большом цикле работ 1969-78 гг. В. С. Владимировым были изучены голоморфные функции многих комплексных переменных с положительной мнимой частью в трубчатых областях над конусами (в частности, в трубе будущего): их рост, граничные свойства и интегральные представления, обобщающие классическое представление Неванлинны. Эти результаты были использованы Василием Сергеевичем для построения теории многомерных линейных пассивных систем (1969-79 гг.). Линейные пассивные системы описываются матрицами обобщённых функций, удовлетворяющих так называемому условию пассивности относительно телесного конуса, предложенному Василием Сергеевичем. Пассивность означает, что рассматриваемая физическая система подчиняется условию причинности относительно конуса и способна лишь поглощать или рассеивать энергию, но не генерировать её. В этой области им доказано существование фундаментального решения у любой невырожденной пассивной системы, причём это решение само удовлетворяет условию пассивности относительно того же конуса, выведены дисперсионные соотношения, исследована обобщённая задача Коши, установлена связь с матрицей рассеяния. Эти результаты вошли в его монографию «Обобщённые функции в математической физике» (1976, 1979 гг., переведена на английский, французский, итальянский языки).

Василия Сергеевича отличала широта научных интересов. Он с удивительной легкостью переключался на новые области, активно работал со своими учениками. В 1963 г. он совместно с М. Ширинбековым занимался построением оболочек голоморфности для областей типа Гартогса. В 1980 г. он совместно с В. В. Жариновым получает общую формулу для законов сохранения (локальных и нелокальных). В работах 1985 г. совместно с А. Г. Сергеевым разрабатывает комплексный анализ в трубе будущего.

Работы по автомодельному поведению в квантовой теории поля 1972 г. послужили стимулом для работ Василия Сергеевича по многомерному обобщению тауберовой теоремы Харди-Литтлвуда (1976 г.), а проблематика, связанная с поведением Фурье-образа форм-факторов в окрестности светового конуса, была продолжена в совместных работах с Б. И. Завьяловым (198182 гг.). Совместно с Ю. Н. Дрожжиновым и Б. И. Завьяловым Василий Сергеевич развивает многомерную тауберову теорию для обобщённых функций. Эти результаты и их применения в квантовой теории поля, в комплексном анализе, в теории дифференциальных уравнений и в пассивных системах подытожены в их совместной монографии «Многомерные тауберовы теоремы для обобщённых функций» (1986 г., Наука; перевод на английский язык 1988 г., Kluwer).

В серии совместных с И. В. Воловичем работ были развиты следующие направления.

Исследованы две модели статистической физики. Первая - диофантовы свойства меры Ли-Янга, описывающей распределение нулей статистической суммы для ферромагнитной модели Изинга с магнитным полем (1982г.). Вторая - полное решение гауссовой модели на полуоси с взаимодействием, задаваемым тёплицевой формой. Это был первый пример модели с несуммируемым взаимодействием, для которого доказано существование свободной энергии (1983 г.).

Построен анализ функций от коммутирующих и антикоммутирующих 
переменных - суперанализ. Результаты нашли применение в суперсимметричной теории поля, в частности, к суперсимметричному уравнению ЯнгаМиллса, теории струн и теории операторов на суперпространствах.

Предложен общий метод построения законов сохранения (локальных и нелокальных) для линейных и нелинейных интегро-дифференциальных уравнений, нашедший широкое применение в математической физике, в частности, к уравнению Навье-Стокса, уравнению переноса, проблемам экологии, суперсимметричному уравнению Янга-Миллса. На его основе разработан метод малого параметра для получения бесконечной цепочки законов сохранения для двумерных интегрируемых систем (1984г.).

Исследование гауссовой модели послужило для Василия Сергеевича стимулом к разработке теории обобщённых решений (в классах ультрараспределений) уравнения Винера-Хопфа и задачи Римана-Гильберта в классах Неванлинны и Смирнова (1984 г.).

Совместно с И. В. Воловичем и Е. И. Зеленовым Василий Сергеевич заложил основы нового направления в современной математической физике $p$-адической математической физики. Ими была предложена формулировка $p$-адической квантовой механики, проведён полный спектральный анализ $p$ адического квантового осциллятора и вычислены все его вакуумные состояния, заложены основы теории $p$-адических операторов, проведён спектральный анализ операторов типа Шрёдингера (1990-92 гг.). Результаты исследований по $p$-адической математической физике подытожены в их монографии «p-Адический анализ и математическая физика» (1994г., Наука, World Scientific.). Василием Сергеевичем был определён и изучен оператор дробного дифференцирования и интегрирования $D^{a}$ (с символом $|x|_{p}$ ), теперь его называют оператором Владимирова. Для этого оператора им впервые была построена полная система собственных функций и собственных значений в $L_{2}\left(\mathbb{Q}_{p}\right)$. При этом оказалось, что собственные функции принадлежат пространству Брюа-Шварца, а собственные значения имеют бесконечную кратность и две точки сгущения: 0 и 1. Здесь существенно проявилось различие в спектральных теориях между вещественным и $p$-адическим случаями.

В серии работ, начиная с 1993 г., Василием Сергеевичем на основе общей формулы Тейта были выведены регуляризованные адельные формулы для древесных струнных и суперструнных амплитуд (обобщающих амплитуды Венециано и Вирасоро) в любом поле алгебраических чисел и для любых мультипликативных характеров. Более детальные формулы были получены для поля рациональных чисел и для одноклассных квадратичных полей. Для описания древесных безмассовых суперструнных амплитуд В. С. Владимировым была введена новая бета-функция для любого поля характеристики нуль (2002 г.).

В совместной работе В. С. Владимирова и г. И. Марчука (ДАН, 2000 г.) дано определение сопряжённого оператора для нелинейных задач и указаны их некоторые применения. Эта работа подытожила предыдущие работы авторов и заложила фундамент многих дальнейших работ в данной области.

В 2002 г. вышла в свет монография В .С. Владимирова "Methods of the Theory of Generalized Functions" (Taylor and Francis) на английском языке. Она подтверждает высказывания П. Дирака (1930г.) и Н. Н. Боголюбова (1963 г.) о математизации физических наук. 
Последние десять лет научные интересы Василия Сергеевича связаны с новым классом нелинейных операторов и соответствующих уравнений, к которым относятся эффективные уравнения динамики $p$-адической струны. В частности, им доказан ряд теорем о существовании и несуществовании непрерывных решений краевых задач для уравнения динамики $p$-адической струны, установлены новые оценки и свойства решений краевых задач для этих уравнений. Получены необходимые и достаточные условия квадратичной интегрируемости производной от решения, установлен ряд новых свойств решений, описывающих динамику тахионов для $p$-адических замкнутых и открытых струн, получены оценки решений и возможные способы их построения, установлена связь между числом перемен знака и максимальной кратностью нулей решения. Найдены новые точные решения для многомерных уравнений движения тахионов для открытых и замкнутых $p$-адических струн.

В. С. Владимиров окончил университет по кафедре теории чисел, а затем многие годы занимался вопросами, далёкими от неё. Но в последние годы его научные интересы вновь оказались связанными с теорией чисел. Это является хорошим подтверждением любимого тезиса Василия Сергеевича о единстве теоретической и прикладной математики. Его научному творчеству присущи как глубина и сила результатов, так и разнообразие тематики: от решения прикладных задач численными методами до р-адической квантовой теории поля. Создаваемые им математические теории вырастали, как правило, из актуальных задач физики и техники, что всегда было характерно для лучших традиций отечественной математической школы.

Василий Сергеевич вёл большую педагогическую работу. В течение многих лет он был профессором Московского физико-технического института, читал созданный им на базе обобщённых функций новый курс уравнений математической физики. По его всемирно известному учебнику «Уравнения математической физики» (Наука, изд. I-V, 1967-88 гг.), переведённому во всех ведущих странах мира, обучаются как в нашей стране, так и за её пределами. В. С. Владимиров - соавтор и редактор «Сборника задач по уравнениям математической физики» (Наука, изд. I-III, 1974-2001 гг., переведён на 5 языков), существенно дополняющего учебник. Также издан сокращённый и переработанный вариант учебника для ВТУЗов (2000 г., совм. с В. В. Жариновым). В. С. Владимиров редактировал 1-й том (математика) 12-томного собрания научных трудов Н. Н. Боголюбова и написал вводную статью «Николай Николаевич Боголюбов и математическая физика».

Василий Сергеевич - активный пропагандист математической науки. Его статьи в газетах и научно-популярных журналах ярко и просто и в то же время на высоком научном уровне рассказывают о сложных проблемах современной математической физики. Им совместно с И. И. Маркушем написана брошюра о выдающемся учёном, математике и механике, организаторе советской науки - академике В. А. Стеклове (1973-81 гг.), которая переведена на английский и испанский языки. В 1990 г. им выпущена научно-популярная брошюра «Обобщённые функции и их применение» («Знание»). Василий Сергеевич возглавлял Всероссийские олимпиады школьников по математике, физике и химии (и впоследствии - биологии) (1975-83 гг.), а также секцию по математике в комиссиях по премиям Ленинского комсомола (1972-75 гг.) 
и по премиям Ленинского комсомола Подмосковья (1982-85 гг.). Он являлся членом Комиссии по школьному математическому образованию при Отделении математики (1979-1983 гг.), принимал активное участие в дискуссиях по проблемам школьного математического образования.

В. С. Владимиров пользуется широкой международной известностью. Его высокий научный авторитет давал ему возможность продуктивно содействовать развитию международных научных связей. Василий Сергеевич возглавлял советские делегации на Генеральные ассамблеи Международного математического союза (Варшава, 1983 г., Беркли, 1986 г.). Он - иностранный член Саксонской Академии наук (Лейпциг), Сербской Академии наук и искусств (Белград), Воеводинской Академии наук и искусств (Нови Сад). Академия наук Чехословакии удостоила его золотой медали Бернарда Больцано. Василий Сергеевич был избран почётным членом Чехословацкого общества математиков и физиков (Прага). Он являлся членом Московского математического общества, Международной ассоциации по математической физике (IAMP), Американского математического общества (AMS) и членом редколлегий ряда ведущих математических журналов, председателем комиссии Академии наук по присуждению золотой медали П. Л. Чебышева (с 1988 г.).

В. С. Владимиров принимал активное участие в организации ряда крупных международных конгрессов и конференций, вместе с Н. Н. Боголюбовым положил начало международным конгрессам по математической физике (Москва, 1972 г.). В. С. Владимиров был одним из инициаторов и активно участвовал в подготовке и организации трех международных конференций по математической физике и её приложениям в Самаре (Самара, 2008, 2010, 2012 гг.)

Он был приглашённым докладчиком на Международном конгрессе математиков (Ницца, 1970 г.). Совместно с Н. Н. Боголюбовым представил пленарный доклад на конгресс в Эдинбурге в 1958 г.

В 1968 г. В. С. Владимиров избран членом-корреспондентом Академии наук СССР, в 1970 г. - действительным членом (академиком) Академии наук CCCP.

Василий Сергеевич проводил большую работу в Отделении математики Академии наук, с 1971 по 2002 гг. он был членом Бюро, а в 1980-1987 гг. - заместителем академика-секретаря Отделения. С 1975 по 1988 гг. он возглавлял Экспертный совет по математике и механике ВАК СССР.

В. С. Владимиров - один из основателей журнала «Теоретическая и математическая физика». В составе его редколлегии - с 1969 г., из них 21 год заместитель главного редактора. В течение 24 лет он работал в редколлегии журнала «Доклады Академии наук», 1993-2002 гг. - заместитель главного редактора. С 1971 г. Василий Сергеевич - член редколлегии, а с 1983 по 2002 гг. - главный редактор журнала «Известия Академии наук. Серия математическая». С 1975 по 1991 гг. он - член Секции по математике и механике Комитета по Ленинским и Государственным премиям в области науки и техники при Совете Министров СССР, причём с 1987 по 1991 гг. её председатель. С 1970 г. В. С. Владимиров - член Группы по математике при Секции РИСО (впоследствии НИСО) издательства «Наука», а с 1988 по 1992 гг. - её председатель. С 1980 года он - член Национального комитета советских (впоследствии российских) математиков. С 1987 по 1991 годы- 
координатор раздела «Математика» Советско-Индийского научно-технического сотрудничества. В 1993-99 гг. Василий Сергеевич был председателем Әкспертного совета по математике по Государственным научным стипендиям при Президиуме РАН.

С 1948 г. творческая деятельность В. С. Владимирова связана с Математическим институтом им. В. А. Стеклова. Много сил он отдаёт поддержанию научных традиций института, атмосфере творческой увлечённости. В 1969 г. он организовал и возглавил отдел Математической физики, в 1988 г. он организовал по предложению Н. Н. Боголюбова общеинститутский семинар по математике и её приложениям и являлся одним из его руководителей. В 1988 г. коллектив института избрал Василия Сергеевича на пост директора. За большие заслуги в развитии науки и подготовке научных кадров В. С. Владимиров был удостоен звания Героя Социалистического Труда, он награждён двумя орденами Ленина, орденом Отечественной войны, двумя орденами Трудового Красного Знамени и многими медалями. Он - лауреат Сталинской (1953 г.) и Государственной (1978 г.) премий. В 1997 г. Президиум НАН Украины присудил Василию Сергеевичу премию Боголюбова, а в 1999 г. Президиум РАН - золотую медаль Боголюбова.

В Василии Сергеевиче прекрасно сочетались академическая, фундаментальная подготовка учёного и живой ум гражданина и руководителя.

Учёный, администратор, преподаватель, Учитель, Человек. . . . Не только авторитет выдающегося учёного и глубина знаний привлекали к нему людей. Работая с ним, сотрудники и коллеги с уважением относились к его требовательности, трудоспособности, порядочности, ценили в нём натуру умную и тонкую.

У Василия Сергеевича было и остаётся много искренних почитателей его личности и таланта, людей, обязанных ему своим становлением в науке и в жизни вообще.

Светлая память о выдающемся учёном и учителе навсегда сохранится в наших сердцах.

Заведующий отделом математической физики Математического института им. В. А. Стеклова Российской Академии наук, член-корреспондент РАН, доктор физико-математических наук, И. В. Волович. 